ORIGINAL ARTICLE

\title{
Patients undergoing coronary revascularisation: a missed opportunity for secondary prevention?
}

\author{
D J Fox, M Kibiro, J Eichhöfer, N P Curzen
}

Postgrad Med J 2005;81:401-403. doi: 10.1136/pgmj.2004.023861

See end of article for authors' affiliations

.....................

Correspondence to: Dr D J Fox, Manchester Heart Centre, Manchester Royal Infirmary, Oxford Road, Manchester M13 9WL, UK; david.j.fox@ talk21.com

Submitted 10 May 2004 Accepted

17 September 2004

\begin{abstract}
Background: This study tested the hypothesis that the opportunity to start secondary prevention therapy before discharge after coronary revascularisation is being missed. The study assessed current prescribing practice and identified discrepancies in prescribing for patients managed by surgeons (especially) and cardiologists.

Methods: 200 consecutive patients from the Manchester Heart Centre percutaneous coronary intervention (PCI) and coronary artery bypass (CABG) registries were identified ( 100 from each registry) and the notes analysed. All had undergone coronary revascularisation from February 2002 to March 2002. Data were analysed using SPSS for Windows, version 10.1.

Results: After exclusion of two patients with contraindications, 100\% (98 of 98) of $\mathrm{PCl}$ patients and $92 \%$ (90 of 98) CABG patients were prescribed aspirin at discharge. Eight two per cent of eligible $\mathrm{PCl}$ patients and $70 \%$ of eligible CABG patients were prescribed $\beta$ blockers at discharge. Ninety six per cent $(96$ of 100 ) of $\mathrm{PCl}$ patients and 73\% (73 of 100) of CABG patients were prescribed statins of any dose at discharge, $(p<0.001)$. Sixty five per cent of $P C I$ but only $26 \%$ of CABG patients were discharged prescribed ACE inhibitors (eligible patients based on HOPE, heart outcomes prevention evaluation trial), $(\mathrm{p}<0.001)$.

Conclusions: Secondary prevention prescription after coronary revascularisation remains suboptimal in all but aspirin use. Patients in the $\mathrm{PCl}$ group were statistically more likely to be discharged prescribed a statin or an ACE inhibitor, or both, than patients after CABG. Both interventional cardiologists and (especially) cardiac surgeons must improve their use of secondary prevention therapy.
\end{abstract}

C ardiovascular disease is a leading cause of premature mortality and morbidity in the United Kingdom causing over 235000 deaths due in the year $2000 .{ }^{1}$ The improvement in symptoms achieved by both percutaneous coronary intervention (PCI) and coronary artery bypass graft (CABG) is unequivocally proved. In addition, both techniques can improve prognosis in certain patient groups. $^{2}$ As a result, the number of these procedures has grown substantially in the UK, with the latest figures suggesting a ratio of 1.7:1 PCI to CABG. In terms of long term prognosis, however, clinical studies have shown important prognostic benefits from medical treatment in large subgroups of patients with coronary artery disease or left ventricular dysfunction.

In the case of statins, consistent prognostic benefit is shown in studies that include secondary prevention populations. ${ }^{3-7}$ Some of these data include specific subgroups who have undergone coronary revascularisation. ${ }^{5}$ Furthermore, any patient with left ventricular dysfunction ${ }^{89}$ or sharing the inclusion criteria of the HOPE study ${ }^{10}$ is expected to benefit prognostically from an ACE inhibitor. This would therefore include most patients undergoing coronary revascularisation. It has previously been shown that there is poor uptake of ACE inhibitor therapy after CABG. ${ }^{11}$ The benefit of aspirin is already well established in patients with coronary disease ${ }^{12} 13$ as are the data favouring $\beta$ blockers in those with previous myocardial infarction or ongoing ischaemia. ${ }^{14-16}$

Thus, data suggest that most patients undergoing PCI or CABG will benefit in the long term from prescription of aspirin, statin, ACE inhibitor, and, in many cases, $\beta$ blocker. The episode of the admission for revascularisation clearly represents an ideal opportunity to achieve this drug strategy. The responsibility for achieving this benefit would ideally lie with the consultant supervising the revascularisation: either interventional cardiologist or cardiac surgeon. Many patients who undergo CABG are now only followed up by the cardiac surgical team, which makes it an important part of their responsibility, independent of the referring cardiologist.

The objectives of this study were therefore as follows:

- To identify total discharge prescriptions of four key confirmed secondary preventative drugs in 100 consecutive PCI and 100 consecutive CABG patients.

- To assess if prescribing of the four drugs is optimal in the two revascularisation groups.

- To analyse the differences, if any, between the two clinician groups in prescribing trends to see if coronary revascularisation patients are getting the same treatment from interventional cardiologists and cardiothoracic surgeons.

The hypothesis to be tested was therefore that the opportunity to provide optimal, evidence based secondary prevention after coronary revascularisation is not being taken.

\section{METHODS}

A retrospective study was performed analysing 100 consecutive notes for each group from the Manchester Heart Centre registries of PCI and CABG between February 2002 and March 2002. All patients referred for surgical revascularisation had previously been seen by a cardiologist. Case note analysis was undertaken to elicit secondary preventative drugs patients were taking before admission and at discharge after revascularisation. Demographic data were also recorded

Abbreviations: $\mathrm{PCl}$, percutaneous coronary intervention; $\mathrm{CABG}$, coronary artery bypass graft 


\begin{tabular}{|c|c|c|c|c|}
\hline & & $\mathrm{PCl}$ group (\%) & CABG group (\%) & p Value \\
\hline Aspirin & $\begin{array}{l}\text { Before admission } \\
\text { Discharge }\end{array}$ & $\begin{array}{l}82 \\
100\end{array}$ & $\begin{array}{l}87 \\
92\end{array}$ & $\begin{array}{l}\text { NS } \\
\text { NS }\end{array}$ \\
\hline Statin & $\begin{array}{l}\text { Discharge } \\
\text { Before admission } \\
\text { Discharge }\end{array}$ & $\begin{array}{l}67 \\
96\end{array}$ & $\begin{array}{l}79 \\
73\end{array}$ & $\begin{array}{l}\text { NS } \\
<0.001\end{array}$ \\
\hline ACE inhibitor & $\begin{array}{l}\text { Before admission } \\
\text { Discharge }\end{array}$ & $\begin{array}{l}32 \\
65\end{array}$ & $\begin{array}{l}32 \\
26\end{array}$ & $\begin{array}{l}\text { NS } \\
<0.001\end{array}$ \\
\hline$\beta$ Blocker & $\begin{array}{l}\text { Before admission } \\
\text { Discharge }\end{array}$ & $\begin{array}{l}60 \\
82\end{array}$ & $\begin{array}{l}72 \\
70\end{array}$ & $\begin{array}{l}\text { NS } \\
\text { NS }\end{array}$ \\
\hline
\end{tabular}

as well as coronary risk factors, number of vessels revascularised via PCI or CABG, length of hospital stay, and any report of drug contraindication/reason for non-prescription.

All data was stored using ExCEL software and analysed using SPSS for Windows version 10.1 for statistical analysis. According to statistical advice, Fisher's exact test was used to compare results between PCI and CABG patients. Paired Student's $t$ test was used to determine significant differences between the two groups (PCI and CABG).

RESULTS (SUMMARISED IN TABLE 1 AND FIGURE 1) Seventy four of the PCI group and 82 of the CABG group were male. The mean age of the patients was 62 years for men and 64 years for women. The age range was from 40 to 81 years in the PCI group and 40 to 88 years in the CABG group.

\section{Aspirin prescription}

Eight two per cent of PCI patients and $87 \%$ of the CABG group were taking aspirin before admission.

At discharge $100 \%$ of all eligible (98 of 100) PCI patients but only $92 \%$ (90 of 98 ) of the eligible CABG patients were taking aspirin of any dose.

\section{Statin prescription}

Sixty seven per cent of PCI patients and $79 \%$ of the CABG patients were prescribed statins before admission $(p=0.079)$. At discharge $96 \%$ of the PCI patients were discharged prescribed a statin compared with $73 \%$ of CABG patients, $(p<0.001)$.

In this study serum cholesterol measurements were available in the notes for 175 patients (91 CABG patients and 84 PCI patients). Many patients had had their cholesterol concentration reading taken before admission for coronary revascularisation. The mean cholesterol concentration for the CABG patient population was $4.7 \mathrm{mmol} / \mathrm{l}$ whereas the mean for the PCI group was $5.0 \mathrm{mmol} / \mathrm{l}$. The median total cholesterol concentration for both groups was $4.7 \mathrm{mmol} / \mathrm{l}$.

\section{ACE inhibitor prescription}

In all, $60(30 \%)$ patients took ACE inhibitors before admission for revascularisation and $81(40 \%)$ patients were discharged taking the same treatment. Twenty nine per cent of PCI patients and $31 \%$ of CABG patients were taking ACE inhibitor treatment at admission.

The proportion of patients discharged on ACE inhibitors was $56 \%$ in the PCI group compared with $25 \%$ in the CABG patients $(\mathrm{p}<0.001)$, representing a reduction in discharge prescriptions of ACE inhibitors in the surgical group.

In keeping with the recent findings from the HOPE study, all patients with established CHD aged 55 years and over had an indication for an ACE inhibitor, regardless of left ventricular function. In our study population, there were 150 patients aged 55 years and over who were eligible for such treatment (68 of 150 PCI and 82 of 150 CABG). When this subgroup of patients was analysed, 48 of 150 (33\%) patients were taking ACE inhibitors on admission. At discharge, this proportion doubled among the PCI patients, so that $65 \%$ (44 of 68 ) of patients were being treated with ACE inhibitors. By contrast, in the CABG group the proportion decreased to $26 \%$ (21 of 82 ). Specifically, 14

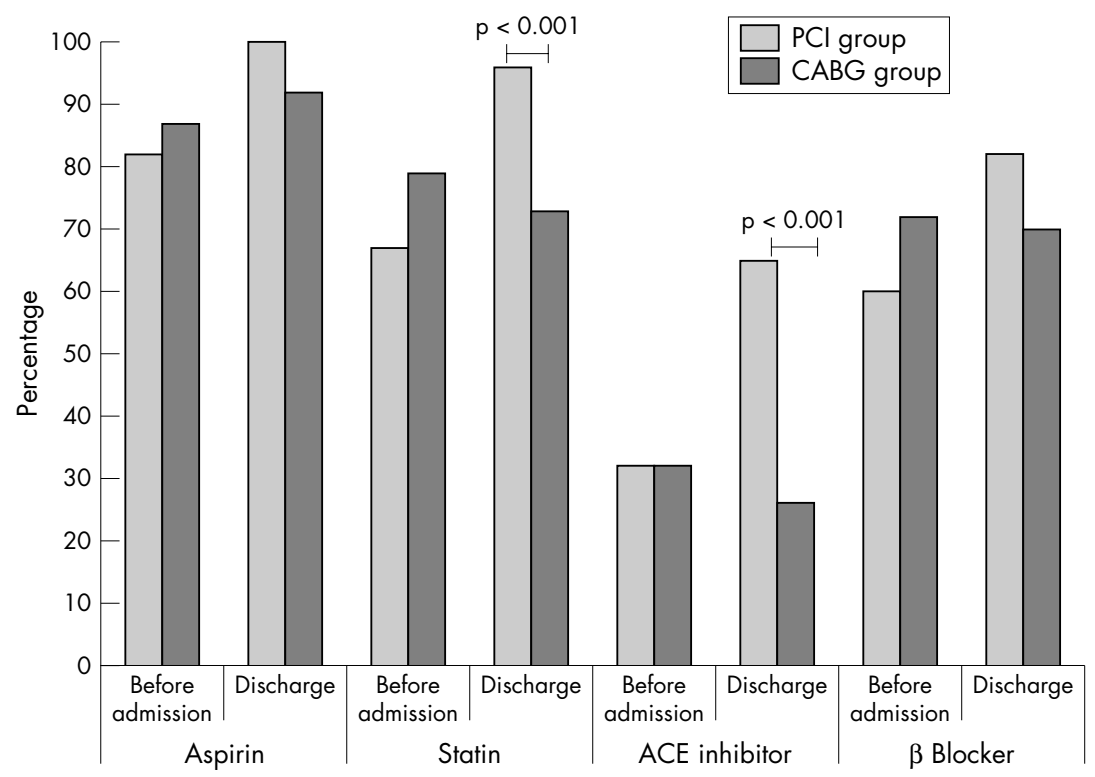

Figure 1 Results of the study summarised in a histogram. 
CABG patients who had been taking ACE inhibitors before admission were discharged home without them.

\section{B blocker prescription}

After excluding eight patients who had contraindications to $\beta$ blockers, 127 of the remaining $192(66 \%)$ patients were taking these agents before admission to hospital. At discharge, this total increased to 146 of $192(76 \%)$ patients. This included $60 \%$ ( 56 of 94) of eligible PCI patients admitted already prescribed $\beta$ blockers and $72 \%$ (69 of 98) eligible CABG patients admitted taking $\beta$ blockers.

In the PCI group, six patients had clear contraindications to $\beta$ blockers. After they were excluded, 77 of the remaining $94(82 \%)$ patients were discharged home prescribed $\beta$ blockers. There were two CABG patients with contraindications to $\beta$ blocker therapy. After excluding these patients, 71 of the remaining $98(72 \%)$ patients were taking these agents before admission. This proportion decreased to $70 \%$ (69 of 98 eligible patients) at discharge. Therefore, at discharge $82 \%$ (77 of 94) of PCI patients were prescribed $\beta$ blockers as compared with $70 \%$ (69 of 98) of CABG patients $(p=0.153)$.

\section{DISCUSSION}

We failed to disprove the null hypothesis that secondary prevention therapy after revascularisation remains suboptimal according to the contemporary evidence base. It has been well established in the literature that all patients should be taking aspirin ${ }^{12}{ }^{13}$ and all patients after myocardial infarction or with significant left ventricular dysfunction should be taking a $\beta$ blocker. ${ }^{14}{ }^{16}$ In addition, according to $\mathrm{CARE}^{5}$ and the heart protection study, ${ }^{7}$ all such patients should be taking at least $40 \mathrm{mg}$ of either simvastatin or pravastatin (or an equivalent). At the time the patients in this study underwent revascularisation the $\mathrm{HOPE}^{10}$ study suggested that as well as all patients with left ventricular dysfunction, all revascularisation patients over 55 years should be also be taking an ACE inhibitor. Since that time, the recently published EUROPA study $^{18}$ suggests that all coronary artery disease patients, regardless of age, should be taking ACE inhibitor.

In our study, while aspirin prescription is satisfactory in both PCI and CABG patients at discharge, and comparable to the ASPIRE data, ${ }^{17}$ the discharge prescription of statin, ACE inhibitor, and $\beta$ blocker remains suboptimal.

This study therefore shows that both cardiologists and surgeons are not making the most of this opportunity for secondary prevention. In particular, patients treated by CABG surgery have comparatively low discharge rates for statins and ACE inhibitors, and alarmingly there was a trend in statin, ACE inhibitor, and $\beta$ blocker therapy for less patients in the CABG group to be discharged prescribed these drugs than were actually admitted to hospital taking them.

This highlights an important clinical issue: all clinicians who undertake revascularisation, including interventional cardiologists and cardiac surgeons, need to be trained to take responsibility for this secondary prevention as part of the revascularisation "package" that they provide. The traditional attitude that the cardiac surgeon does not get involved with the patient's drug treatment is now out of date and the current and next generation of trainees in this specialty should understand the importance of this aspect of the care that they provide. This philosophy has become particularly important because increasingly cardiologists (many of whom are performing higher volume revascularisation procedures in their own right) do not see post-CABG patients again themselves, so that all follow up is undertaken by the surgical team.

The timing of the introduction of these agents is likely to be important. The revascularisation episode itself represents a unique opportunity to capture the population who require secondary prevention when they can be educated and, importantly, when they are well motivated. For example, Aronow et al ${ }^{19}$ showed that inpatient introduction of lipid lowering drugs was a strong, significant positive predictor of continued use at six months. This finding can almost certainly be extrapolated for all drug treatment started in hospital.

In conclusion this study highlights a missed opportunity for secondary prevention. Interventional cardiologists and cardiac surgeons alike should now be using these agents as a default at discharge to optimise the care that they provide for these patients.

\section{Authors' affiliations}

D J Fox, M Kibiro, J Eichhöfer, Manchester Heart Centre, Manchester Royal Infirmary, Manchester, UK

N P Curzen, Wessex Cardiac Unit, Southampton University Hospitals, Southampton, UK

Funding: none.

Conflicts of interest: none declared.

\section{REFERENCES}

1 Department of Health. National Service Framework for coronary heart disease. London: HMSO, 2000.

2 Archbold RA, Curzen NP. The role of revascularisation in the treatment of acute coronary syndromes: who should you refer? Clin Med 2004;4:32-5.

3 Scandinavian Simvastatin Survival Study Group. Randomised trial of cholesterol lowering in 4444 patients with coronary heart disease: the Scandinavian simvastatin survival study (4S). Lancet 1994;344:1383-9.

4 Sacks FM, Pfeffer MA, Moye LA, et al. The effects of pravastatin on coronary events after myocardial infarction in patients with average cholesterol levels. N Engl J Med 1996;335:1001-9.

5 Flaker GC, Warnica JW, Sacks FM, et al. Pravastatin prevents clinical events in revascularised patients with average cholesterol concentrations. J Am Coll Cardiol 1999;34:106-12.

6 The Long-Term Intervention with Pravastatin in Ischaemic Disease (LIPID) Study Group. Prevention of cardiovascular events and death with pravastatin in patients with coronary heart disease and a broad range of initial cholesterol levels. N Engl J Med 1998;339:1349-57.

7 Heart Protection Study Collaborative Group. MRC/BHF heart protection study of cholesterol lowering with simvastatin in 20,536 high-risk individuals: a randomised placebo-controlled trial. Lancet 2002;360:7-22.

8 Pfeffer MA, Braunwald E, Moye LA, et al, on behalf of the SAVE Investigators. Effect of captopril on mortality and morbidity in patients with left ventricular dysfunction after myocardial infarction: results of the survival and ventricular enlargement trial. N Engl J Med 1992;327:669-77.

9 The Acute Infarction Ramipril Efficacy (AIRE) Study Investigators. Effect of ramipril on mortality and morbidity of survivors of acute myocardial infarction with clinical evidence of heart failure. Lancet 1993;342:821-8.

10 The Heart Outcomes Prevention Evaluation (HOPE) Study Investigators. Effects of an angiotensin-converting-enzyme inhibitor, ramipril, on cardiovascular events in high-risk patients. N Engl J Med 2000;342:145-53.

11 Archbold A, Zaman A, Curzen N, et al. Prescribing of angiotensin enzyme inhibitors and statins after $C A B G$ : a missed opportunity for secondary prevention. British Journal of Cardiology 2003;10:36-44.

12 Antiplatelet Trialists' Collaboration. Collaborative overview of randomised trials of antiplatelet therapy. 1. Prevention of death, myocardial infarction and stroke by prolonged antiplatelet therapy in various categories of patients. BMJ 1994:308:81-106.

13 Antiplatelet Trialists' Collaboration. Collaborative meta-analysis of randomised trials of antiplatelet therapy for prevention of death, myocardial infarction and stroke in high risk patients. BMJ 2002;324:71-86.

14 Freemantle N, Cleland J, Young P, et al. $\beta$ Blockade after myocardial infarction: systematic review and meta regression analysis. BMJ 1999;318:1730-7.

15 Gottlieb SS, McCarter RJ, Vogel RA. Effects of $\beta$ blockade on mortality among low and high risk patients after myocardial infarction. N Engl J Med 1998:339:489-97.

16 Doughty RN, Rodgers A, Sharpe N, et al. Effects of $\beta$ blocker therapy on mortality in patients with heart failure. A systematic overview of randomised controlled trials. Eur Heart J 1997; 18:560-5.

17 Aspire Steering Group. A British Cardiac Society survey of the potential for secondary prevention of coronary disease: ASPIRE (action on secondary prevention through intervention to reduce events). Principal results. Heart 1996;75:334-42

18 Fox KM. European trial on reduction of cardiac events with perindopril in stable coronary artery disease investigators (the EUROPA study). Lancet 2003;362:782-8

19 Aronow HD, Novaro GM, Laver MS, et al. In hospital initiation of lipidlowering therapy after coronary intervention as a predictor of long term utilisation. Arch Intern Med 2003;163:2576-82. 